\title{
Avaliação de indicadores para estimativa das digestibilidades parciais e total de dietas em bovinos ${ }^{1}$
}

\section{Rodolfo Marques de Brito ${ }^{2}$, Alexandre Amstalden Moraes Sampaio ${ }^{3}$, Kleber Tomás de Resende, Alexandre Rodrigo Mendes Fernandes ${ }^{4}$, Wignez Henrique ${ }^{5}$, Karina de Souza Routman ${ }^{6}$}

\author{
1 Parte da tese do primeiro autor apresentada à FCAV/Unesp, Jaboticabal, SP. \\ 2 UNIRP, São José do Rio Preto, SP. \\ ${ }^{3}$ Departamento Zootecnia/FCAV/Unesp, Jaboticabal, SP. Bolsista CNPq. \\ ${ }^{4}$ Doutorando pela FCAV/Unesp, Jaboticabal, SP. \\ 5 Apta Regional, São José do Rio Preto, SP. \\ ${ }^{6}$ Mestre pela FCAV/Unesp, Jaboticabal, SP.
}

RESUMO - Avaliaram-se os indicadores fibra detergente ácido indigestível (FDAi) e óxido crômico $\left(\mathrm{Cr}_{2} \mathrm{O}_{3}\right)$ na estimativa das digestililidades parciais e total das frações nutritivas da dieta. Foram utilizados quatro tourinhos Santa Gertrudes canulados no rúmen e no duodeno, distribuídos em delineamento quadrado latino $4 \times 4$ (animais $\times$ período) para estimativa da digestibilidade de quatro dietas compostas de feno de capim-marandu e concentrados, ajustadas para proporcionar ganho de peso corporal diário de 0,5 e $1 \mathrm{~kg}$ /animal e potencial de fermentação microbiana de 9,5 e $11 \mathrm{~g}$ de PB microbiana/MJ EM fermentável. Os suplementos foram formulados com mistura mineral, milho, soja e farelos de soja e algodão. Não houve interação significativa dietas $\times$ indicadores. À exceção dos coeficientes de digestibilidade intestinal da MS e da FDN, todos os outros coeficientes de digestibilidade (MS, PB e CT) diferiram significativamente entre os indicadores avaliados. Quando utilizado o indicador FDAi, foram registrados maiores valores de digestibilidade ruminal e total e menores coeficientes de digestibilidade intestinal. A FDAi possibilitou melhor estimativa dos coeficientes de digestibilidade dos nutrientes das dietas, quando compostas na sua maior parte de volumosos (57 a $70 \%$ da MS).

Palavras-chave: digestibilidade intestinal, digestibilidade ruminal, fibra em detergente ácido indigestível, óxido crômico

\section{Evaluation of markers for estimating ruminal, intestinal and total tract digestibility of nutrients in cattle}

\begin{abstract}
Four Santa Gertrudis young bulls fitted with ruminal and duodenal cannula were randomly assigned to a 4 x 4 Latin square to compare ruminal, intestinal, and total tract digestibility of nutrients estimated by the internal marker indigestible acid detergent fiber (IADF) or by the external marker chromic oxide $\left(\mathrm{Cr}_{2} \mathrm{O}_{3}\right)$. Animals were fed palisadegrass hay (Brachiaria brizantha $\mathrm{cv}$. Marandu) and concentrates formulated to allow daily body weight gain of 0.5 and $1 \mathrm{~kg}$ and potential of microbial fermentation of 9.5 and $11 \mathrm{~g}$ of microbial crude protein/MJ of fermentable metabolizable energy. Concentrates contained mineral mixture, ground corn, ground soybean, soybean and cottonseed meals. There was no significant interaction between diets and markers. Except for the apparent intestinal digestibility coefficients of dry matter and neutral detergent fiber, all remaining (OM, CP, and TC) digestibility coefficients differed significantly comparing IADF with $\mathrm{Cr}_{2} \mathrm{O}_{3}$. When IADF was used, ruminal and total tract digestibility of nutrients were greater while intestinal digestibility was lower compared to $\mathrm{Cr}_{2} \mathrm{O}_{3}$. Indigestible ADF yielded the best estimates of nutrient digestibility coefficients in diets with high proportion of forage (57 to $70 \%$ of total DM)
\end{abstract}

Key Words: chromic oxide, indigestible acid detergent fiber, intestinal digestibility, ruminal digestibility

\section{Introdução}

A determinação da digestibilidade das frações nutritivas de dietas por meio de ensaios com coleta total de fezes tem sido empregada ao longo dos anos. Trata-se de um método experimental trabalhoso e oneroso, principalmente quando realizado com animais de grande porte, como bovinos, por exigir a manipulação de grandes volumes de amostras.

Por isso, há vários anos, vem sendo proposta a utilização de indicadores ou marcadores, embasada no emprego de uma substância que, fazendo parte dos alimentos (indicador interno) ou sendo fornecida separadamente (indicador externo), deve ser totalmente recuperada nas fezes 
(Silva et al., 1968). A tentativa é simplificar a metodologia experimental e estimar com relativa precisão a quantidade de alimento consumida, a taxa de passagem da digesta e a digestibilidade dos nutrientes no todo ou em parte do trato digestório (Oliveira et al., 1991).

Em revisão sobre indicadores de digestão, Owens \& Hanson (1992) compilaram o comportamento de 13 tipos de indicadores quanto às dez principais características envolvidas no seu uso: facilidade de preparação, utilidade para estudo de fluxo de digesta, melhor fração da digesta a ser avaliada, utilidade para estudo de cinética ruminal, absorção, migração entre fases, migração para bactérias, biossíntese, protocolo de análise e, por último, acurácia de determinação.

$\mathrm{O}$ óxido crômico $\left(\mathrm{Cr}_{2} \mathrm{O}_{3}\right)$ tem sido o indicador externo mais utilizado na estimativa da digestibildade dos nutrientes, mas, em muitos casos, a recuperação não foi satisfatória, o que gerou coeficientes baixos ou até negativos (Oliveira Jr. et al., 2002). Por outro lado, Ferret et al. (1999) não observaram diferenças entre a coleta total de fezes e o óxido crômico na determinação da digestibilidade dos nutrientes.

A presença dos indicadores internos no alimento $\mathrm{e}$ sua distribuição uniforme na digesta constituem vantagem sobre os indicadores externos (Piaggio et al., 1991). Lippke et al. (1986) sugeriram a utilização das frações fibrosas indigestíveis do alimento para esse fim (Lippke et al., 1986), entre elas, a fibra indigestível em detergente neutro (FDNi) e a fibra indigestível em detergente ácido (FDAi), a lignina em detergente ácido (Lig), a lignina em detergente ácido indigestível (Lig-i), a celulose potencialmente indigestível, a cinza insolúvel em ácido (CIA) e a cinza insolúvel em detergente ácido (CIDA). Esses indicadores exigem longos períodos de incubação (Van Soest, 1994), que podem ser in situ ou in vitro. Berchielli et al. (2000) compararam alguns indicadores incubados por 72 e 144 horas e concluíram que a incubação por 72 horas subestimou os coeficientes de digestibilidade de MS, $\mathrm{PB}, \mathrm{EE}, \mathrm{FDN}, \mathrm{EB}$ e NDT. Além disso, segundo esses autores, a FDAi incubada por 144 horas, como sugerido por Lippke et al. (1986) e Van Soest (1994), possibilitou resultados semelhantes aos obtidos pela coleta total de fezes. Por outro lado, Detmann et al. (2001) observaram que esse indicador estimou valores inferiores de digestibilidade das frações nutritivas quando comparado à digestibilidade in vitro. Saliba et al. (1999), no entanto, comparando diversos indicadores internos e externos ao método de coleta total de fezes, verificaram que a média obtida com a FDAi foi mais próxima da encontrada pela coleta total, sugerindo que esse indicador teria grande potencial para ser utilizado em dietas com grande quantidade de forragens, em decorrência do baixo custo e da fácil determinação metodológica. Outros autores têm demonstrado que a FDAi e a coleta total de fezes resultam em estimativas aproximadas da digestibilidade dos nutrientes e, portanto, são metodologias adequadas para esse fim (Zeoula et al., 2001; Alves et al., 2003).

Assim, objetivou-se neste trabalho comparar dois tipos de indicadores, o óxido crômico e a FDAi, na avaliação das digestibilidade aparentes parciais e total dos nutrientes de dietas com feno de capim-marandu e concentrados, balanceadas para proporcionar dois níveis de ganho de peso e dois níveis de síntese microbiana em tourinhos Santa Gertrudes.

\section{Material e Métodos}

O ensaio foi conduzido no Setor de Bovinocultura de Corte e no Laboratório de Ruminantes na Faculdade de Ciências Agrárias e Veterinárias - Unesp, Campus de Jaboticabal, SP. A unidade está localizada na região norte do estado de São Paulo (21 $1^{\circ} 15$ ' 22' ' de latitude Sul e 48 $18^{\circ}$ ' $58^{\prime}$ ', de longitude Oeste). A altitude local é de $595 \mathrm{~m}$ e o clima, segundo a classificação de Köppen, é do tipo subtropical, com chuvas de verão e inverno relativamente seco. As médias anuais de precipitação pluviométrica, temperatura e umidade relativa do ar foram $1.400 \mathrm{~mm}, 21^{\circ} \mathrm{C}$ e $70 \%$, respectivamente.

O piquete de Brachiaria brizantha cv. Marandu selecionado para confecção do feno utilizado neste trabalho foi mantido sob pastejo durante o período chuvoso e recebeu adubação de manutenção de $130 \mathrm{~kg}$ de N/ha, parcelada em quatro aplicações. Após o período de adubação, seguido de um ciclo de pastejo com desfolha de intensidade média, a área foi vedada ao acesso dos animais por aproximadamente 30 dias, antes do processo de fenação. Com esse procedimento, pretendeu-se simular a atividade de pastejo dos animais durante a estação seca.

Foram utilizados quatro tourinhos Santa Gertrudes de $380 \mathrm{~kg}$ de peso corporal e 17 meses de idade. Os animais foram canulados no rúmen e no duodeno, segundo técnica descrita por Leão \& Coelho da Silva (1980), e receberam os tratamentos necessários no pré e no pós-operatório, a fim de garantir a plena recuperação do processo cirúrgico.

Após essa recuperação, os animais foram alojados em baias individuais de alvenaria $\left(16 \mathrm{~m}^{2}\right)$ equipadas com cocho, bebedouro e saleiro exclusivos. Foram avaliadas quatro dietas experimentais, balanceadas para proporcionar dois potenciais de fermentação microbiana (y): alto (11 g de PB microbiana/MJ de EM fermentável) e baixo (9,5 g de PB microbiana/MJ de EM fermentável); e dois 
potenciais de ganho diário de peso corporal (GPC): 0,5 e $1,0 \mathrm{~kg}$ /animal. A análise dos ingredientes utilizados e a composição das dietas são apresentadas nas Tabelas 1 e 2, respectivamente.

O período experimental teve duração de 64 dias, subdivididos em quatro períodos de 16 dias, sendo os sete primeiros de adaptação à dieta, dois dias de coleta de fezes e digesta duodenal, dois de coleta de conteúdo ruminal e os últimos quatro de incubação in situ.

Durante todo o período experimental, os animais receberam feno ad libitum, parcelado em duas refeições ao dia (7 e 17h), e concentrado, fornecido apenas na primeira refeição do dia, de acordo com cada tratamento. Os animais foram pesados no início e ao final do ensaio com jejum total de 15 horas.

Todos os dias, pela manhã, as sobras de alimento nos cochos foram quantificadas e amostradas de forma representativa, para controle da quantidade de alimento consumida pelos animais. As amostras diárias formaram uma amostra composta por animal e por período, sendo mantidas acondicionadas em congelador a $-20^{\circ} \mathrm{C}$.

Comparou-se a digestão dos nutrientes estimada pela fibra em detergente ácido indigestível (FDAi) como indicador interno (Penning \& Jonhson, 1983) e pelo óxido crômico como indicador externo (Williams et al., 1962). Para estimativa das digestibilidades total e parcial das frações nutritivas das rações, utilizaram-se os procedimentos descritos por Sampaio et al. (2000) e Berchielli et al. (2000), com as modificações propostas por Ítavo et al. (2002b). $\mathrm{O} \mathrm{Cr}_{2} \mathrm{O}_{3}$ foi fornecido em dose diária de $10 \mathrm{~g} /$ animal durante o período de adaptação e nos dias de coleta para cálculo da digestibilidade.

A digesta duodenal foi coletada via cânula e as fezes foram coletadas diretamente do piso, às $10 \mathrm{~h}$ no primeiro dia e às $16 \mathrm{~h}$ no segundo dia de coleta, para evitar o estresse causado nos animais pela coleta no reto. Esse procedimento

Tabela 1 - Composição bromatológica dos ingredientes utilizados

Table 1 - Chemical composition of dietary ingredients

\begin{tabular}{|c|c|c|c|c|c|c|c|c|}
\hline \multirow[t]{3}{*}{$\begin{array}{l}\text { Ingrediente } \\
\text { Ingredient }\end{array}$} & \multirow{3}{*}{$\begin{array}{l}\text { MS } \\
D M \\
(\%)\end{array}$} & $\begin{array}{l}\text { MO } \\
O M\end{array}$ & $\begin{array}{l}\mathrm{PB} \\
C P\end{array}$ & $\begin{array}{l}\mathrm{EE} \\
E E\end{array}$ & \multirow{3}{*}{$\begin{array}{c}\text { MM } \\
M M \\
\% \text { da MS } \\
\% D M\end{array}$} & \multirow[t]{3}{*}{$\begin{array}{r}\mathrm{CT} \\
\text { TC }\end{array}$} & \multirow{3}{*}{$\begin{array}{l}\text { FDN } \\
N D F\end{array}$} & \multirow[t]{3}{*}{$\begin{array}{c}\text { FDA } \\
A D F\end{array}$} \\
\hline & & & & & & & & \\
\hline & & & & & & & & \\
\hline Feno capim-marandu (Palisadegrass hay) & 90,08 & 94,72 & 5,65 & 0,74 & 5,28 & 88,32 & 81,55 & 47,54 \\
\hline Milho em grão moído (Ground corn grain) & 87,27 & 99,40 & 11,10 & 3,92 & 0,60 & 84,38 & 26,86 & 4,23 \\
\hline Farelo de algodão (Cottonseed meal) & 89,96 & 93,79 & 45,81 & 1,36 & 6,21 & 46,62 & 28,42 & 20,66 \\
\hline Farelo de soja (Soybean meal) & 90,22 & 93,67 & 51,40 & 1,93 & 6,33 & 40,35 & 22,08 & 11,86 \\
\hline
\end{tabular}

Tabela 2 - Composição dos concentrados e características das dietas experimentais

Table 2 - Ingredient composition of the concentrates and chemical composition of the experimental diets

\begin{tabular}{|c|c|c|c|c|}
\hline \multirow[t]{2}{*}{$\begin{array}{l}\text { Composição dos concentrados }(\%) \\
\text { Ingredient composition of the concentrates (\%) }\end{array}$} & \multicolumn{2}{|c|}{$\begin{array}{l}\text { Baixo GPC } \\
\text { Low } B W G\end{array}$} & \multicolumn{2}{|c|}{$\begin{array}{l}\text { Alto GPC } \\
\text { High } B W G\end{array}$} \\
\hline & $\begin{array}{l}\text { Baixo y } \\
\text { Low y }\end{array}$ & $\begin{array}{l}\text { Alto y } \\
\text { Highy }\end{array}$ & $\begin{array}{l}\text { Baixo y } \\
\text { Low y }\end{array}$ & $\begin{array}{l}\text { Alto y } \\
\text { High y }\end{array}$ \\
\hline Milho em grão moído (Ground corn grain) & 47,4 & 33,3 & 50,8 & 27,8 \\
\hline Farelo de algodão (Cottonseed meal) & 20,7 & 20,7 & 13,1 & 13,1 \\
\hline Farelo de soja (Soybean meal) & 5,8 & 19,9 & 19,6 & 42,6 \\
\hline \multicolumn{5}{|l|}{$\begin{array}{l}\text { Características da dieta } \\
\text { Chemical composition of the diet }\end{array}$} \\
\hline $\mathrm{PB}(\%$ da $\mathrm{MS})(C P, \%$ of $D M)$ & 11,8 & 13,6 & 14,3 & 15,2 \\
\hline $\mathrm{EM}(\mathrm{MJ} / \mathrm{kg}$ de $\mathrm{MS})(M E, M J / k g$ of $D M)$ & 9,4 & 9,4 & 10,1 & 10,0 \\
\hline
\end{tabular}

GPC - Ganho diário de peso corporal estimado: alto ( $1 \mathrm{~kg} /$ animal) e baixo $(0,5 \mathrm{~kg} / \mathrm{animal})$.

y - Potencial de fermentação microbiana estimado: alto (11 g de PB microbiana/MJ de EM fermentável) e baixo $(9,5 \mathrm{~g}$ de PB metabolizável/MJ de EB fermentável).

$B W G$ - Estimated daily body weight gain: high (1 kg/animal) and low (0.5 kg/animal).

Estimated potential of microbial fermentation: high (11 g of microbial CP/MJ of fermentable ME) and low (9.5 g of microbial CP/MJ of fermentable ME).

${ }^{1}$ Níveis de garantia por kg (Guaranty levels, by kg):Ca - $271 \mathrm{~g} ; \mathrm{P}-29 \mathrm{~g} ; \mathrm{Mg}-20 \mathrm{~g} ; \mathrm{S}-31 \mathrm{~g} ; \mathrm{Na}-62 \mathrm{~g} ; \mathrm{Zn}-1.350 \mathrm{mg} ; \mathrm{Cu}-340 \mathrm{mg} ; \mathrm{Fe}-1.064 \mathrm{mg} ; \mathrm{Mn}-$ 940 mg; Co - 10 mg; I - 25 mg; Se - 10 mg. 
não prejudicou a qualidade e o horário das coletas, pois o piso foi lavado com água diariamente e os animais defecaram em quantidade suficiente logo após sua contenção com cabrestos.

As amostras foram acondicionadas em sacos plásticos e mantidas em congelador, devidamente identificadas. Ao final do período, cada amostra de digesta e de fezes foi liofilizada e moída para formação de amostras compostas por animal e por período para análise de FDAi e $\mathrm{Cr}_{2} \mathrm{O}_{3}$. A FDAi foi obtida após 144 horas de incubação do material no rúmen (Penning \& Jonhson, 1983) e o óxido crômico foi determinado por espectrofotometria de absorção atômica em comprimento de onda de $426 \mathrm{~nm}$, fenda 0,5 e corrente $8 \mathrm{~mA}$, conforme técnica de Williams et al. (1962). Parte desse material, juntamente com as amostras de alimento e sobras, também foi analisada quanto aos teores de MS, PB e cinzas, segundo AOAC (1995), e quanto às concentrações de FDN e FDA, conforme Van Soest et al. (1991). Os teores de MO foram determinados pela diferença obtida com o teor de cinzas e o de CT, conforme Sniffen et al. (1992), a fim de possibilitar a determinação da ingestão, do fluxo e da excreção de nutrientes pelo animal, bem como os coeficientes de digestibilidade. Todas as análises foram realizadas no Laboratório de Ruminantes da FCAV/Unesp, Campus de Jaboticabal, SP.

As médias foram estudadas em modelo de quadrado latino 4 x 4 (animais x períodos), com quatro dietas e dois marcadores (FDAi e $\mathrm{Cr}_{2} \mathrm{O}_{3}$ ), tendo sido estudada a interação dietas $\times$ indicadores. Foi realizada análise de variância por meio do teste F (Sampaio, 1998).

\section{Resultados e Discussão}

Este trabalho fez parte de um conjunto de experimentos (Brito, 2004) nos quais foi simulada a situação de bovinos mantidos em pastagem de Brachiaria brizantha cv. Marandu durante a estação seca recebendo suplementação com concentrado em regime de semiconfinamento.

As médias dos consumos de MS e MO e a porcentagem de volumoso dos tratamentos obtidas durante todo o período experimental são apresentadas na Tabela 3 .

O volumoso consistiu no principal componente da dieta (Tabela 3), em proporção de 57 da $70 \%$ da MS.

$\mathrm{Na}$ análise estatística dos dados obtidos neste trabalho, não foram encontrados efeitos significativos da interação dietas $\times$ indicadores para nenhuma das variáveis estudadas. Assim, os resultados apresentados na comparação entre os indicadores estudados correspondem à média dos coeficientes de digestibilidade das quatro dietas estudadas.

Na Tabela 4 encontra-se a comparação das metodologias de estimativa dos coeficientes de digestibilidade ruminais das frações nutritivas das dietas utilizando-se os indicadores FDAi e $\mathrm{Cr}_{2} \mathrm{O}_{3}$.

Quando empregada a FDAi, foram verificados maiores valores $(\mathrm{P}<0,01)$ de digestibilidade ruminal para todos os nutrientes avaliados. Ítavo et al. (2002b), por outro lado, não observaram diferenças na estimativa da digestibilidade da MS pela FDAi ou pelo óxido crômico e, portanto, consideraram que esses indicadores foram adequados para estimar o fluxo de MS e as digestibilidades ruminais. Valadares Filho et al. (1985b), por sua vez, ao compararem o $\mathrm{Cr}_{2} \mathrm{O}_{3}$ e a lignina na determinação dos fluxos de digesta

Tabela 3 - Porcentagem de volumoso e ingestão diária de MS e MO de feno e concentrado nos diferentes potenciais de fermentação e produção

Table 3 - $\quad$ Proportion of dietary forage and daily intake of DM and OM of hay and concentrates

\begin{tabular}{|c|c|c|c|c|}
\hline \multirow{3}{*}{$\begin{array}{l}\text { Item } \\
\text { Item }\end{array}$} & \multirow{2}{*}{\multicolumn{2}{|c|}{$\begin{array}{l}\text { GPC } \\
B W G \\
\end{array}$}} & \multirow{2}{*}{\multicolumn{2}{|c|}{$\mathrm{y}$}} \\
\hline & & & & \\
\hline & $\begin{array}{c}\text { Baixo } \\
\text { Low }\end{array}$ & $\begin{array}{l}\text { Alto } \\
\text { High }\end{array}$ & $\begin{array}{c}\text { Baixo } \\
\text { Low }\end{array}$ & $\begin{array}{l}\text { Alto } \\
\text { High }\end{array}$ \\
\hline Porcentagem de volumoso (Proportion of dietary forage) & 69,6 & 57,5 & 63,0 & 63,4 \\
\hline Ingestão MS de feno (kg/animal) (Hay DM intake, kg/animal) & 4,9 & 4,6 & 4,8 & 4,8 \\
\hline Ingestão MS de feno (\% $\left.\mathrm{PC}^{1}\right)($ Hay DM intake, $\%$ BW $)$ & 1,2 & 1,1 & 1,2 & 1,2 \\
\hline Ingestão MS concentrado (\% PC) (Concentrate intake, \% BW) & 0,6 & 0,9 & 0,8 & 0,8 \\
\hline Ingestão MS total (kg/animal) (Total DM intake, (kg/animal) & 7,0 & 8,1 & 7,6 & 7,6 \\
\hline Ingestão MS total (\% PC) (Total DM intake, \% BW) & 1,7 & 2,0 & 1,9 & 1,9 \\
\hline Ingestão MS total ( $\left.\mathrm{g} / \mathrm{kg} \mathrm{PC} \mathrm{PC}^{0,75}\right)$ (Total DM intake, $\mathrm{g} / \mathrm{kg} B W^{0.75}$ ) & 77,8 & 89,5 & 83,6 & 83,7 \\
\hline Ingestão MO total (kg/animal) (Total OM intake, kg/animal) & 6,7 & 7,7 & 7,2 & 7,2 \\
\hline
\end{tabular}

GPC - Ganho diário de peso corporal estimado: alto (1 $\mathrm{kg} / \mathrm{animal})$ e baixo $(0,5 \mathrm{~kg} / \mathrm{animal})$.

y - Potencial estimado de fermentação microbiana: alto (11 g de PB microbiana/MJ de EM fermentável) e baixo (9,5 g de PB metabolizável/MJ de EM fermentável).

${ }^{1} \mathrm{PC}$ - Peso corporal.

BWG - Estimated daily body weight gain: high (1 kg/animal) and low (0.5 kg/animal).

Estimated potential of microbial fermentation: high (11 g of microbial CP/MJ of fermentable $M E)$ and low (9.5 g of microbial CP/MJ of fermentable ME)

${ }^{1} B W$ - Body weight. 
Tabela 4 - Coeficientes de digestibilidade ruminal estimados utilizando-se fibra em detergente ácido indigestível (FDAi) e óxido crômico $\left(\mathrm{Cr}_{2} \mathrm{O}_{3}\right)$, em porcentagem do ingerido

Table 4 - Apparent ruminal digestibility coefficients estimated by indigestible acid detergent fiber (IADF) and chromic oxide $\left(\mathrm{Cr}_{2} \mathrm{O}_{3}\right)$, as percentage of intake

\begin{tabular}{|c|c|c|c|c|}
\hline $\begin{array}{l}\text { Coeficiente de } \\
\text { digestibilidade } \\
\text { Digestibility } \\
\text { coefficient }\end{array}$ & $\begin{array}{l}\text { FDAi } \\
I A D F\end{array}$ & $\mathrm{Cr}_{2} \mathrm{O}_{3}$ & $\begin{array}{c}\text { Teste } \mathrm{F}^{1} \\
F \text { test }\end{array}$ & $\mathrm{CV}(\%)$ \\
\hline $\operatorname{MS}(D M)$ & 49,2 & 22,2 & $* *$ & 42,63 \\
\hline $\mathrm{MO}(O M)$ & 56,0 & 31,9 & $* *$ & 27,61 \\
\hline $\mathrm{PB}(C P)$ & 44,1 & 15,9 & $* *$ & 58,78 \\
\hline $\mathrm{CT}(T C)$ & 46,3 & 17,2 & $* *$ & 46,76 \\
\hline $\operatorname{FDN}(N D F)$ & 63,5 & 41,4 & $* *$ & 22,73 \\
\hline
\end{tabular}

${ }^{1 * *}$ significativo a $1 \%$ de probabilidade (Significant at $1 \%$ of probability).

Tabela 5 - Coeficientes de digestibilidade intestinal, em porcentagem do ingerido, estimados utilizando-se fibra em detergente ácido indigestível (FDAi) e óxido crômico $\left(\mathrm{Cr}_{2} \mathrm{O}_{3}\right)$

Table 5 - Apparent intestinal digestibility coefficients estimated by indigestible acid detergent fiber (IADF) and chromic oxide $\left(\mathrm{Cr}_{2} \mathrm{O}_{3}\right)$

\begin{tabular}{|c|c|c|c|c|}
\hline $\begin{array}{l}\text { Coeficiente de } \\
\text { digestibilidade } \\
\text { Digestibility } \\
\text { coefficient }\end{array}$ & $\begin{array}{l}\text { FDAi } \\
I A D F\end{array}$ & $\mathrm{Cr}_{2} \mathrm{O}_{3}$ & $\begin{array}{c}\text { Teste } \mathrm{F}^{1} \\
\quad F \text { test }\end{array}$ & $\mathrm{CV}(\%)$ \\
\hline $\operatorname{MS}(D M)$ & 13,0 & 28,6 & NS & 54,11 \\
\hline $\mathrm{MO}(O M)$ & 8,2 & 21,5 & $*$ & 63,74 \\
\hline $\mathrm{PB}(C P)$ & 26,0 & 47,7 & $*$ & 24,58 \\
\hline $\mathrm{CT}(T C)$ & 9,9 & 26,1 & $*$ & 64,01 \\
\hline $\mathrm{FDN}(N D F)$ & $-1,5$ & 7,9 & NS & $1.454,47$ \\
\hline
\end{tabular}

${ }^{1}$ NS - não significativo, * significativo a $5 \%$ de probabilidade.

${ }^{1} \mathrm{NS}$ - not significant, * significant at $5 \%$ of probability.

em novilhos com 16 meses de idade e $206 \mathrm{~kg}$, também concluíram que o $\mathrm{Cr}_{2} \mathrm{O}_{3}$ subestimou a digestão ruminal da MS. Esses autores utilizaram coleta de digesta durante seis dias, às 9 e 15h. Berchielli et al. (1996) relataram baixa recuperação de óxido crômico no duodeno, o que resultou em subestimativa da digestão ruminal da MS. Mendes et al. (2005) relataram resultados de FDAi com coeficientes de digestibilidade ruminais da MS significativamente superiores aos estimados pela FDNi, Lig e Lig-i.

A comparação das metodologias de estimativas de digestão intestinal das frações nutritivas das dietas utilizando como indicadores o $\mathrm{Cr}_{2} \mathrm{O}_{3}$ e a FDAi é representada na Tabela 5. À exceção da digestibilidade intestinal da MS e da $\mathrm{FDN}$, que foram semelhantes $(\mathrm{P}>0,05)$ entre as metodologias, houve diferenças significativas entre os indicadores nas médias estimadas para os demais nutrientes. Com o indicador FDAi, as médias de digestibilidade intestinal aparente $(\mathrm{P}<0,05)$ para MO, PB e CT foram menores.
Como os resultados neste trabalho, Ítavo et al. (2002b) não detectaram diferenças na estimativa da digestibilidade intestinal aparente da MS quando compararam esses mesmos indicadores. Berchielli et al. (1998), no entanto, concluíram que indicadores externos, quando comparados à FDAi e à FDNi, superestimaram o fluxo de MS duodenal e, conseqüentemente, subestimaram os valores de digestibilidade. Essas mesmas conclusões foram obtidas por Valadares Filho et al. (1985a), em estudo no qual testou óxido crômico como indicador. Os resultados divulgados por Mendes et al. (2005) demonstraram que a digestibilidade intestinal da MS estimada pela FDAi e pela FDNi foram semelhantes, mas inferiores às obtidas utilizando-se a $\mathrm{Lig}$ e a $\mathrm{Lg}$-i.

Não se espera que a fração FDN seja digerida no intestino delgado, o que, talvez, tenha sido a razão dos baixos coeficientes de digestibilidade intestinal obtidos na estimativa pelo óxidocrômico e dos coeficientes negativos estimados pela FDAi. Oliveira Jr. et al. (2002) também não obtiveram recuperação satisfatória do óxido crômico em caprinos.

Na Tabela 6 são apresentadas as digestibilidades totais das frações nutritivas obtidas pelos indicadores estudados.

Quando estimados pela FDAi, os coeficientes de digestibilidade total dos componentes nutritivos foram maiores $(\mathrm{P}<0,01)$ que com o $\mathrm{Cr}_{2} \mathrm{O}_{3}$. Como observado neste trabalho, Berchielli et al. (2000) também relataram que a FDAi incubada por 144 horas foi um indicador adequado e semelhante à coleta total de fezes na estimativa da digestilidade total da MS, PB e FDN em dietas com 55\% de volumoso na MS. Ítavo et al. (2002a) recomendaram a utilização da FDAi como indicador na estimativa da digestilidade dos nutrientes quando compararam esse indicador à FDNi, visto que a FDAi resultou em coeficientes de digestibilidade maiores e mais próximos ao esperado para alguns nutrientes. Esses autores compararam os indicadores utilizando animais Nelore e dietas formuladas exclusivamente com feno ou com níveis crescentes de concentrado (20 a 80\%). Saliba et al. (1999) compararam diversos indicadores internos e externos à coleta total de fezes e concluíram que o uso da FDAi é a metodologia mais promissora, visto que os valores médios obtidos para digestibilidade da MS foram os mais próximos da coleta total.

Zeoula et al. (2002) consideraram a FDAi um bom indicador para estimar a digestibilidade da MS e da MO de dietas com $50 \%$ da MS em forma de feno e níveis de substituição do milho pela farinha de varredura, apesar de sua recuperação nas fezes ter sido próxima a $90 \%$. Os coeficientes de digestibilidade estimados com este indicador foram semelhantes aos estimados com CIA, FDNi e pela coleta total de fezes. 
Tabela 6 - Coeficientes de digestibilidade total (\%) estimados com a fibra em detergente ácido indigestível (FDAi) e o óxido crômico $\left(\mathrm{Cr}_{2} \mathrm{O}_{3}\right)$

Table 6 - Apparent total tract digestibility coefficients estimated by indigestible acid detergent fiber (IADF) and chromic oxide $\left(\mathrm{Cr}_{2} \mathrm{O}_{3}\right)$

\begin{tabular}{llllr}
\hline $\begin{array}{l}\text { Coeficiente de } \\
\text { digestibilidade } \\
\begin{array}{l}\text { Digestibility } \\
\text { coefficient }\end{array}\end{array}$ & $\begin{array}{l}\mathrm{FDAi} \\
\text { IADF }\end{array}$ & $\mathrm{Cr}_{2} \mathrm{O}_{3}$ & $\begin{array}{r}\text { Teste } \mathrm{F}^{1} \\
\text { Ftest }\end{array}$ & $\mathrm{CV}(\%)$ \\
\hline MS $(D M)$ & 61,8 & 51,2 & $* *$ & 11,04 \\
$\mathrm{MO}(O M)$ & 64,1 & 54,2 & $* *$ & 9,76 \\
$\mathrm{~PB}(C P)$ & 71,3 & 63,4 & $* *$ & 8,34 \\
$\mathrm{CT}(T C)$ & 56,3 & 44,2 & $* *$ & 14,04 \\
$\mathrm{FDN}(N D F)$ & 60,1 & 49,5 & $* *$ & 16,35 \\
\hline
\end{tabular}

$1 * \star$ significativo a $1 \%$ de probabilidade (significant at $1 \%$ of probability).

Freitas et al. (2002) concluíram que a FDAi e o óxido crômico podem ser utilizados como indicadores na estimativa da produção fecal, observando-se que a FDAi pode ser obtida pela incubação in vitro ou in situ, enquanto o indicador FDNi não foi adequado. Na estimativa do fluxo duodenal de MS e MO, ambos os indicadores internos foram recomendados. Utilizando óxido crômico, no entanto, o fluxo de MS foi superestimado. Os coeficientes de digestibilidade dos nutrientes (MS, MO, PB, EE, CT, FDN, FDA e CNF) foram semelhantes quando estimados pela coleta total de fezes ou pela FDAi, conforme os resultados obtidos por Alves et al. (2003) com ovinos recebendo dietas com $50 \%$ de volumoso na MS. Esses autores concluíram que a FDAi pode ser utilizada como indicador interno para estimativa de digestibilidade em ovinos.

Por outro lado, Véras et al. (2005) concluíram que a FDAi, em comparação à coleta total de fezes, subestimou os coeficientes de digestibilidade dos nutrientes e que a FDNi consiste em um indicador eficiente na determinação da digestibilidade. Esses autores utilizaram ovinos e dietas com 50\% da MS em forma de volumoso (feno). Mendes et al. (2005) também concluíram o mesmo sobre o uso de FDNi e FDAi na determinação da digestibilidade total da MS, visto que a estimativa da MO digerida no rúmen utilizan do-se a FDNi foi mais próxima àquela calculada por equação. Apesar disso, os valores dos coeficientes de digestibilidade não foram estatisticamente diferentes entre esses indicadores, nem em relação à Lig-i.

Oliveira Jr. et al. (2002) obtiveram resultados semelhantes de digestibilidade das frações MS, MO, PB, FDN, FDA e EE, ao utilizarem a coleta total de fezes e o óxido crômico. Esses autores utilizaram bovinos da raça Nelore com peso corporal de $420 \mathrm{~kg}$ e dietas com alto teor de concentrado (apenas $20,5 \%$ de bagaço de cana-de-açúcar) e diferentes fontes nitrogenadas. Ressalta-se que esses autores determinaram o óxido crômico nas fezes por fluorescência de raios-X, o que parece ter influenciado os resultados.

De acordo com Owens \& Hanson (1992), a FDAi e o $\mathrm{Cr}_{2} \mathrm{O}_{3}$ foram semelhantes quanto utilizados no estudo de fluxo (úteis), cinética ruminal (impróprios), absorção (nenhuma), migração entre fases (ausente), migração para bactérias (ausente), biossíntese (ausente) e acurácia (satisfatória). As divergências mantiveram-se entre a facilidade de preparação (considerada simples para $\mathrm{Cr}_{2} \mathrm{O}_{3} \mathrm{e}$ inexistente para FDAi), o método de análise (colorimétrico para $\mathrm{Cr}_{2} \mathrm{O}_{3}$ e gravimétrico para FDAi) e a fração a ser analisada (fibrosa para FDAi e não determinada para $\mathrm{Cr}_{2} \mathrm{O}_{3}$ ).

Nenhuma substância usada como indicador preenche perfeitamente todas as características desejáveis para esse fim (Merchen, 1993) a ponto de ser considerada ideal, mas várias são suficientemente adequadas para fornecer resultados úteis para a nutrição animal. O óxido crômico apresenta algumas limitações, como a variação acentuada de sua excreção nas fezes (Owens \& Hanson, 1992), a propriedade carcinogênica (Peddie et al., 1982) e a baixa recuperação fecal, decorrente da metodologia empregada para sua determinação (Williams et al., 1962), conforme discutido por Curran et al. (1967). Considerando os resultados obtidos e a recomendação de pesquisadores que avaliaram estes indicadores, pode-se afirmar que a FDAi, em comparação ao óxido crômico, apresentou melhor capacidade de representação dos principais conceitos da nutrição de ruminantes quando utilizadas dietas ricas em volumosos.

\section{Conclusões}

Independentemente de as dietas terem sido formuladas para proporcionar diferentes ganhos de peso e potenciais de fermentação microbiana, a estimativa das digestibilidades parciais e total apresentou mesma tendência quando foram utilizados os indicadores óxido crômico e fibra em detergente ácido indigestível.

A fibra em detergente ácido indigestível, em comparação ao óxido crômico, mostrou-se mais adequada para estimativa das digestibilidades parciais e total dos nutrientes em bovinos.

\section{Literatura Citada}

ALVES, K.S.; CARVALHO, F.F.R.; FERREIRA, M.A. et al. Níveis de energia em dietas para ovinos Santa Inês: digestibilidade aparente. Revista Brasileira de Zootecnia, v.32, p.19621968, 2003 (supl. 2).

ASSOCIATION OF OFFICIAL ANALYTICAL CHEMISTS - AOAC. Official methods of analysis. 16.ed. Washington: 1995. v.1, p.1-30. 
BERCHIELLI, T.T.; RODRIGUEZ, N.M.; OLIVEIRA, H.P. Efeito de diferentes relações volumoso:concentrado no consumo, digestibilidade aparente e partição da digestão de dieta de bovinos. Arquivo Brasileiro de Medicina Veterinária e Zootecnia, v.48, n.5, p.607-617, 1996.

BERCHIELLI, T.T.; RODRIGUEZ, N.M.; OSÓRIO NETO, E. et al. Comparação de marcadores de fase sólida para medir fluxo de matéria seca e matéria orgânica no duodeno. Arquivo Brasileiro de Medicina Veterinária e Zootecnia, v.50, n.2, p.147-152, 1998.

BERCHIELLI, T.T.; ANDRADE, P.; FURLAN, C.L. Avaliação de indicadores internos em ensaios de digestibilidade. Revista Brasileira de Zootecnia, v.29, n.3, p.830-835, 2000.

BRITO, R.M. Valor bioeconômico da suplementação alimentar para bovinos em pastagens de Brachiaria brizantha cv. Marandu. Jaboticabal: Universidade Estadual Paulista, 2004. 90p. Tese (Doutorado em Zootecnia) - Universidade Estadual Paulista, 2004.

CURRAN, M.K.; LEADER, J.D.; WESTON, E.W. A note on the use of chromic oxide incorporated in a feed to estimate faecal output in ruminants. Animal Production, v.9, p.561-564, 1967.

DETMANN, E.; PAULINO, M.F.; ZERVOUDAKIS, J.T. et al. Cromo e indicadores internos na determinação do consumo de novilhos mestiços, suplementados, a pasto. Revista Brasileira de Zootecnia, v.30, n.5, p.1600-1609, 2001.

FERRET, A.; PLAIXATS, J.; CAJA, G. et al. Using markers to estimate dry matter digestibility, fecal output and dry matter intake in dairy ewes fed Italian ryegrass hey or alfalfa hay. Small Ruminant Research, v.33, n.2, p.145-152, 1999.

FREITAS, D.; BERCHIELLI, T.T.; SILVEIRA, R.N. et al. Produção fecal e fluxo duodenal de matéria seca e matéria orgânica estimado por meio de indicadores. Revista Brasileira de Zootecnia, v.31, n.3, p.1521-1530, 2002 (supl.).

ÍTAVO, L.C.V.; VALADARES FILHO, S.C.; SILVA, F.F. et al. Consumo, degradabilidade ruminal e digestibilidade aparente de fenos de gramíneas do gênero Cynodon e rações concentradas utilizando indicadores internos. Revista Brasileira de Zootecnia, v.31, n.2, p.1024-1032, 2002a (supl.)

ÍTAVO, L.C.V.; VALADARES FILHO, S.C.; SILVA, F.F. et al. Comparação de indicadores e metodologia de coleta para estimativas de produção fecal e fluxo de digesta em bovinos. Revista Brasileira de Zootecnia, v.31, n.4, p.1833-1839, 2002 b.

LEÃO, M.I.; COELHO DA SILVA, J.F. Técnica de fistulação de abomaso embezerros. In: REUNIÃO ANUAL DA SOCIEDADE BRASILEIRA DE ZOOTECNIA, 17., 1980, Fortaleza.Anais... Fortaleza: Sociedade Brasileira de Zootecnia, 1980. p.37.

LIPPKE, H.; ELLIS, W.C.; JACOBS, B.F. Recovery of indigestible fiber from feces of sheep and cattle on forage diets. Journal of Animal Science, v.69, n.2, p.403-413, 1986.

MENDES, A.R.; EZEQUIEL, J.M.B.; GALATI, R.L. et al. Consumo e digestibilidade total e parcial de dietas utilizando farelo de girassol e três fontes de energia em novilhos confinados. Revista Brasileira de Zootecnia, v. 34, n.2, p.679-691, 2005.

MERCHEN, N.R. Digestion, absorption and excretion in ruminants. In: CHURCH, D.C. (Ed.) The ruminant animal digestive physiology and nutrition. 4.ed. Carvallis: O\&B Books, 1993. p.172-210.

OLIVEIRA, R.F.M.; FONTES, C.A.L.; COELHO DA SILVA, J.F. et al. Estudo da recuperação fecal do óxido crômico e dos indicadores internos CIA, CIDA e lignina em períodos de coleta de dois a sete dias, em bovinos. Revista da Sociedade Brasileira de Zootecnia, v.20, n.5, p.522-531, 1991.

OLIVEIRA JR., R.C.; SUSIN, I.; PIRES, A.V. et al. Desempenho de cabras em lactação alimentadas com grão de soja. Acta Scientiarum, v.24, n.4, p.1113-1118, 2002.

OWENS, F.N.; HANSON, C.F. External and internal markers for appraising site and extent of digestion in ruminants. Journal of Dairy Science, v.75, n.9, p.2605-2617, 1992.
PEDDIE, J.; DEWAR, W.A.; GILBERT, A.B. et al. The use of titanium dioxide for determining apparent digestibility in mature domestic fowls (Gallus domesticus). Journal of Agricultural Science, v.99, p.233-263, 1982.

PENNING, P.D.; JOHNSON, R.H. The use of internal markers to estimate herbage digestibility and intake. 2. Indigestible acid insoluble fiber. Journal of Agricultural Science, v.100, n.1, p.133-138, 1983.

PIAGGIO, L.M.; PRATES, E.R.; PIRES, F.F. et al. Avaliação das cinzas insolúveis em ácido, fibra em detergente ácido indigestível e lignina em detergente ácido indigestível como indicadores internos da digestibilidade. Revista da Sociedade Brasileira de Zootecnia, v.20, n.3, p.306-312, 1991.

SALIBA, E.O.S.; RODRÍGUEZ, N.M.; GONÇALVES, L.C. Estudo comparativo da lignina isolada da palha de milho, com outros indicadores em ensaio de digestibilidade aparente. In: REUNIÃO ANUAL DA SOCIEDADE BRASILEIRA DE ZOOTECNIA, 36. 1999, Porto Alegre. Anais... Porto Alegre: Sociedade Brasileira de Zootecnia, 1999. p.293.

SAMPAIO, A.A.M.; VIEIRA, P.F.; BRITO, R.M. Digestão total e parcial de nutrientes em bovinos alimentados com ração contendo levedura, uréia e farelo de algodão. Revista Brasileira de Zootecnia, v.29, n.2, p.589-597, 2000.

SAMPAIO, I.B.M. Estatística aplicada à experimentação animal. Belo Horizonte: Fundação de Ensino e Pesquisa em Medicina Veterinária e Zootecnia, 1998. 221p.

SILVA, J.F.C.; CAMPOS, J.; CONRAD, J.H. Uso do óxido crômico na determinação da digestibilidade. Experientiae, v.8, n.1, p.1-23, 1968.

SNIFFEN, C.J.; O'CONNOR, J.D.; Van SOEST, P.J. A net carbohydrate and protein system for evaluating cattle diets: II. Carbohydrate and protein availability. Journal of Animal Science, v.70, n.11, p.3562-3577, 1992.

VALADARES FILHO, S.C.; SILVA, J.F.C.; LEÃO, M.I. et al. Óxido crômico e lignina na determinação dos fluxos de matéria seca em bovinos e bubalinos. Revista da Sociedade Brasileira de Zootecnia, v.14, n.5, p.565-574, 1985a.

VALADARES FILHO, S.C.; COELHO DA SILVA, J.F.; LEÃO, M.I. et al. Óxido crômico e lignina na determinação dos fluxos de matéria seca abomasal, ileal e fecal em bovinos e bubalinos. Revista da Sociedade Brasileira de Zootecnia, v.14, n.5, p.565-574, 1985b.

Van SOEST, P.J. Nutritional ecology of the ruminant. 2.ed. New York: Cornell University Press, 1994. 476p.

Van SOEST, P.J.; ROBERTSON, J.B.; LEWIS, B.A. Methods of dietary fiber, neutral detergent fiber, and nonstarch polysaccharides in relation to animal nutrition. Journal of Dairy Science, v.74, n.10, p.3583-3597, 1991.

VÉRAS, R.M.L.; FERREIRA, M.A.; VÉRAS, A.S.C. et al. Substituição do milho por farelo de palma forageira em dietas para ovinos em crescimento. Consumo e digestibilidade. Revista Brasileira de Zootecnia, v.34, n.1, p.351-356, 2005.

WILLIAMS, C.H.; DAVID, D.J.; ILSMAA, O. The determination of chromic oxide in faeces samples by atomic absorption spectrophotometry. Journal of Agricultural Science, v.59, n.1, p.381-385, 1962.

ZEOULA, L.M.; DIAN, P.H.M.; CALDAS NETO, S.F. et al. Avaliação de indicadores internos em ensaios de digestibilidade para ruminantes. In: REUNIÃO ANUAL DA SOCIEDADE BRASILEIRA DE ZOOTECNIA, 38., 2001, Piracicaba. Anais... Piracicaba: Sociedade Brasileira de Zootecnia, 2001. p.1122.

ZEOULA, L.M.; PRADO, I.N.; DIAN, P.H.M. et al. Recuperação fecal de indicadores internos avaliados em ruminantes. Revista Brasileira de Zootecnia, v.31, n.4, p.1865-1874, 2002. 